\title{
LA REFORMA CONSTITUCIONAL Y SUS EFECTOS EN LAS RELACIONES IGLESIA-ESTADO
}

\author{
María del Carmen García Aguilar
}

\section{Introducción}

A poco más de una década de la reforma de los artículos constitucionales $3^{\circ}, 5^{\circ}, 24,27$-fracciones II y III-y 130, esta comunicación intenta identificar los impactos sociopolíticos gestados por esta nueva legalidad en las relaciones Estado-iglesias. Como se recordará, el nuevo marco jurídico generó un amplio debate entre quienes asumieron la reforma como un hecho positivo acorde a los cambios de la sociedad nacional y quienes opinaron lo contrario, en tanto implicaba legitimar la participación de las iglesias, particularmente la Iglesia católica, en la vida pública del país. El tiempo ha terminado por colocar a ambas posiciones en su lugar, pues a la luz de las realidades de las entidades federativas los impactos se tornan no sólo más complejos, sino también bastante particularizados, en atención al mosaico material y cultural que caracteriza al territorio nacional.

Chiapas, la entidad menos católica del país y la que registra la mayor diversidad religiosa (INEGI, 1990 y 2000), es un espacio de disputas identitarias, entre las que destacan las de naturaleza religiosa. La reforma constitucional de 1992 que dota de personalidad jurídica a las instituciones religiosas y las iguala con las asociaciones civiles

María del Carmen García Aguilar, investigadora del CESMECA-UNICAH en derechos y obligaciones, marca un punto de inflexión no sólo en los enfoques del estudio de las instituciones eclesiales sino también, en el hecho religioso mismo y sus prácticas. En Chiapas, espacio de estas reflexiones, es visible el pluralismo religioso y la disputa por la hegemonía de dicho campo con impactos en el sistema de las identidades colectivas, en tanto su radio de acción discurre en la producción de sentido y de dirección social. Concluimos que con la reforma constitucional las asociaciones religiosas se convierten en espacios estratégicos para regular o configurar otros ámbitos de la sociedad, como el político.

\section{Breve itinerario de las relaciones Estado-iglesias}

Para la sociología clásica las relaciones entre religión y política están mediadas por el proceso de secularización, proceso que si bien no entraña la desaparición de la religión, sí implica la pérdida de centralidad de ésta, tanto en el marco normativo como en el de los sistemas de producción de sentido de la sociedad moderna. El estatuto teórico de la religión se circunscribe a la esfera privada y, por ende, se asume de naturaleza individual y electiva. Desde esta perspectiva, las tensiones o conflictos entre la esfera religiosa y la esfera política, se configu- 
ran como tensiones menores en tanto existe un marco cultural que limita de manera casi natural a ambas esferas. Este modelo, implícito en el reconocimiento secular de la sociedad moderna, difiere en el caso de México, en donde las relaciones entre el Estado y la Iglesia católica históricamente se han manifestado como expresiones de pugnas de poder entre las elites de ambas instituciones y no como expresiones culturales de la sociedad, producto de un proceso sostenido de modernidad.

La historia de las relaciones entre la Iglesia católica y el Estado registra inocultables tensiones que culminaron, a mediados del siglo XIX y durante los primeros años del siglo xx, en un marco jurídico que prácticamente redujo la religión en un asunto privado, liberando a la sociedad de ataduras religiosas y menguando la participación de la Iglesia en prácticamente todas las esferas de la vida social y política (García, 1993; Camp, 1998). La consecuencia inmediata de la radicalización de las medidas liberales en la Constitución mexicana de 1917, fue la rebelión cristera y el enfrentamiento abierto entre la autoridad papal y la jerarquía eclesial nacional con el Estado mexicano. El acuerdo de 1929, conocido como concordato o modus vivendi y la protesta enérgica de Pío XI, en 1932, en la que condenaba el artículo 130 constitucional, son sucesos que manifestaron el grado de polarización al que se había llegado (García, 1993: 14).

Señala Roderic Ai Camp que con el gobierno de Lázaro Cárdenas, pero particularmente con el de Manuel Ávila Camacho ${ }^{2}$, las relaciones entre la Iglesia y el Estado entraron a una etapa de reconciliación, manteniendo la Iglesia católica, en atención a las coyunturas sexenales, una relativa distancia en los asuntos seculares, no así el impulso manifiesto a la feligresía para su participación activa en los asuntos públicos. Sin embargo, el predominio de una relación cupular y elitista, tanto en el desarrollo de las tensiones, como en las negociaciones o acuerdos conciliatorios entre ambas instituciones, tuvo su primera ruptura, desde la institución eclesial mundial y regional, con el Concilio Vaticano II (1962) y, como una derivación de éste, con las reuniones regionales de la Conferencia Episcopal Latinoamericana (CELAM), particularmente la reunión realizada en Medellín, Colombia en 1968.

En México, los impactos prácticos de estos procesos de naturaleza internacional no se dieron ni de manera inmediata ni de manera radical como en otros países de América Latina, ya que como señala Roderic Ai Camp, la jerarquía católica si bien tuvo la oportunidad de atraer para sí el campo de las actividades sociales y el derecho de pronunciarse de manera crítica sobre el gobierno y la política, optó por un comportamiento conservador y conciliatorio con el Estado ${ }^{3}$, y sólo hasta diez años después, cuando la línea teológica que aboga por la defensa de los pobres alcanzó una alta notoriedad, comenzó a concentrarse en los asuntos políticos y económicos. Esta idea es compartida por Martín de la Rosa, quien argumenta que el Concilio Vaticano II "tomó por sorpresa a los obispos mexicanos, haciendo planteamientos bastante ajenos a su estado de ánimo y a su mentalidad [...]" (citado por Concha, et al., 1988: 41).

No obstante, el primero reconoce que los impactos se dieron en la estructura y composición interna de la Iglesia católica mexicana, donde el dominio conservador y homogéneo de la jerarquía eclesial se debilita ante la fuerte emergencia de líneas pastorales que en determinadas coyunturas tenderán a una polarización creciente. Incluso reconoce que los acontecimientos de 1968 provocaron una escisión entre los miembros de la Iglesia, misma que marcó "una crisis en el control social dentro de la institución, en particular en los crecientes conflictos internos de autoridad y en la ruptura de la homogeneidad ideológica estable desde 1929" (Camp, 1998: 49).

En la misma línea, otros estudiosos de la institución eclesial católica, reconocen que tanto la Conferencia Episcopal de Medellín (1968), como la de Puebla (1979), colocaron a la Iglesia en una posición que fue difícil evadir: su definición respecto al antagonismo radical entre 
un sistema de opresión y una lucha de liberación. De acuerdo con estos autores, del Concilio Vaticano II, con su temática de injusticia institucionalizada, nace una nueva institucionalidad eclesial, "una manera concreta de ser Iglesia". Con la encarnación de la Iglesia en las clases populares subalternas, manifiesta en la "opción preferencial por los pobres", de la que emergen las Comunidades Eclesiales de Base (CEB) y la pastoral liberadora:

\footnotetext{
"Se inaugura un nuevo modelo de relación de la Iglesia con la sociedad civil: la relación directa, sin pasar por la mediación del Estado y de las clases dirigentes. La Iglesia se inserta directamente en las clases populares; quiere ser más una Iglesia para el pueblo, con el pueblo y del pueblo, una Iglesia que nace de la fe del pueblo oprimido" (Concha, et al., 1988: 42)
}

En este contexto, la jerarquía debió enfrentar los retos de una Iglesia más plural, que después del Concilio Vaticano II, empezó a expresar de manera abierta sus diferencias teológicas, criticando la visión del cambio social y la posición concreta de la jerarquía católica frente a las coyunturas, particularmente la suscitada por el movimiento estudiantil de 1968, suceso que propició el desafío abierto de un sector reducido pero importante de las filas de la institución católica, destacando el Secretariado Social Mexicano y el liderazgo intelectual de la Iglesia, concentrado en la Compañía de Jesús. Ambas instituciones se enfrentaron a la cúpula católica, convocando a un trabajo de base al lado de los pobres para lograr cambios estructurales. ${ }^{4}$ (Meyer, 1981: 17; Concha, et al., 1988).

Las tensiones internas de la Iglesia católica van a impactar las relaciones Iglesia-Estado. En la década de los setenta, pero particularmente en la de los ochenta, el centro de la discordia estuvo puesto en este sector de la Iglesia católica que practica un "evangelio del hombre que ama al hombre, y que crea la nueva Teología Política, que busca el testimonio del mundo, para condenar lo injusto" (Méndez Arceo, citado por Fazio,1987:13), expresado en líneas de acciones estratégicas como la de la "Iglesia Popular", y proyectos de futuro como el "socialismo democrático", que confrontan tanto al régimen de partido único, como a los tradicionales aliados de la Iglesia católica tradicional y buscan afanosamente el diálogo y la acción conjunta entre cristianos y marxistas, cristianos y socialistas.

Más allá de las posturas extremas que asumió el conflicto entre esta corriente progresista y algunos miembros conservadores de la jerarquía eclesial, el poder institucional, sustentado en el peso de una ideología cristiana preconciliar, resistentes a los cambios fundamentales exigidos por Vaticano II y Medellín, terminó minando el potencial discursivo y práctico de este segmento de la Iglesia, reduciéndolo a dimensiones regionales, aunque con expresiones radicales que inquietarán tanto a la jerarquía católica como al Estado mexicano. ${ }^{6}$

En los años previos a la reforma constitucional, una fracción hegemónica de la jerarquía católica mexicana camina en comunión con la Santa Sede presidida por Juan Pablo II, cuya primera visita a México definió el futuro de las relaciones Iglesia-Estado. Ésta, a la vez que capitaliza algunos de los contenidos del Concilio Vaticano II, para posicionarse, en el marco del proyecto social de la evangelización, como el actor social legítimo responsable de "ofrecer crítica moral y directrices para los que comparten valores católicos en la toma de decisiones específicas sobre cuestiones sociales y políticas", denuncia, critica y mina los postulados de la teología de liberación, que eran el sustento práctico del trabajo pastoral de algunas diócesis y base de su articulación genuina con los movimientos sociales ${ }^{7}$ (Camp, 1988: 52).

\section{La reforma constitucional de 1992: nuevo marco de relaciones Iglesia-Estado}

En abril de 1990 el periódico Excelsior publicó un reportaje con el título "Relaciones Estado-Iglesia. Historia 
de acercamientos y rupturas". ${ }^{8} \mathrm{El}$ ambiente eclesial y político estaba definido por la segunda visita del papa Juan Pablo a realizarse en mayo de ese año y por la percepción, aún no generalizada entre los actores políticos, de una inminente reforma a la Constitución mexicana, propiciando un debate emergente sobre sus posibles implicaciones sociopolíticas. En dicho reportaje, las respuestas de los protagonistas eclesiásticos no dejaban duda de que las relaciones Iglesia- Estado entrarían más temprano que tarde a una etapa inédita para el país.

Para Manuel Olimón, coordinador del Centro de Estudios Históricos de la Universidad Pontificia de México y Agapito Sánchez Preciado, presidente de la Conferencia de Institutos Religiosos de México (CIRM) ${ }^{9}$, los efectos político y social de la visita del Santo Papa eran imprevisibles, no obstante, insistían en que la presencia de Juan Pablo II era prácticamente "un marco de referencia para la XIV Asamblea Nacional del PRI donde se abordaría el tema de las relaciones Iglesia-Estado" señalaron que "la visita podría utilizarse como una coyuntura por los partidos políticos con el objeto de lograr una mayor popularidad entre los mexicanos". ${ }^{10}$

De hecho, entre la primera visita, la de 1989, y la segunda, a realizarse en mayo de 1990, el marco histórico-político que había privado en las relaciones IglesiaEstado había cambiado de manera importante. Desde el seno del gobierno mexicano, se invocaba la modernización del país, modernización que para la jerarquía católica se debía traducir en el fin de las simulaciones. El suceso más relevante, amén de la presencia de miembros de la Iglesia católica en la toma de posesión del Presidente Carlos Salinas en 1988, era no sólo el nombramiento de un representante del presidente ante el Vaticano, sino también, los pronunciamientos cada vez más abiertos de la jerarquía eclesiástica que modulaban y legitimaban una posible reforma constitucional insinuada desde las propias esferas del poder político.

Girolamo Prigione, representante del papa en México, había manifestado que el pueblo de México estaba a favor del reconocimiento jurídico a la Iglesia y de un restablecimiento de las relaciones Iglesia-Estado. Para el obispo de Cuernavaca, Luis Reynoso Cervantes, la decisión del presidente Salinas de nombrar un representante de su gobierno ante el Vaticano, "podría ser un primer paso para el restablecimiento de las relaciones diplomáticas, lo que tácitamente otorgaría un reconocimiento jurídico a la Iglesia Católica”. Desde el Vaticano, monseñor Sergio Obeso, arzobispo de Jalapa y entonces Presidente de la Conferencia Episcopal Mexicana, también había hecho el anuncio de que la reforma al artículo 130 constitucional, ya estaba lista para ser aprobada por el Congreso nacional (Berdejo, 1990).

En el reportaje especial de Excelsior, políticos, académicos e intelectuales, manifestaban incredulidad sobre la posibilidad de un cambio en la constitución que alterara radicalmente las relaciones Iglesia-Estado. Para Ignacio Burgoa Orihuela la designación de un representante del presidente ante el papa no implicaba la modificación o desaparición del artículo 130 constitucional; para Carlos Monsiváis, la entrevista del papa con el presidente era "una visita de cortesía" pues lo fuerte ya se había resuelto, haciendo alusión a las declaraciones, hechas a un periódico nacional, por Fernando Gutiérrez Barrios, Secretario de Gobernación, en el sentido de que no se iba a reformar el artículo 130 constitucional (Excelsior, 12 de febrero, 1990); para Arturo Salcido, presidente entonces del Colegio Nacional de Economistas, era correcto establecer representantes, pero externaba que era "absurdo modificar el artículo 130 constitucional". ${ }^{11}$

Como nos recuerda Martha Eugenia García Ugarte, a finales de 1989, y hasta el momento del reportaje de Exxelsior (abril de 1990), la información gubernamental sobre el tema era confusa y parcial, generando lecturas encontradas entre los actores políticos. Para algunos miembros del Poder Legislativo, la confusión existente demandaba una consulta pública; para otros, dado el sustento histórico del artículo 130 constitucional, lectura 
compartida por muchos actores políticos, intelectuales y juristas, el debate era innecesario (García, 1993: 32).

¿Cuáles eran los sustentos de este optimismo de la jerarquía católica? La búsqueda de respuesta nos conduce al seno de las estructuras y las fuerzas de poder eclesial católico. Cuando Camp (1998) señala que 1979 es el año que marcó un importante cambio en las relaciones Iglesia-Estado, hemos de recordar varios hechos importantes que marcaron la comunión de intereses entre el Vaticano y la jerarquía eclesiástica nacional, aglutinada en la Conferencia Episcopal Mexicana (CEM), bajo el liderazgo del cardenal Emesto Corripio Ahumada. Las muertes de Paulo VI y Juan Pablo I y la asunción del nuevo pontífice Karol Wojtyla, definen una nueva etapa marcada por la búsqueda de un mayor acercamiento con el gobierno y los sectores conservadores de la sociedad nacional, explicitándose la necesidad de revisión del marco jurídico que regula las actividades religiosas en el país.

El comportamiento de la jerarquía eclesial y las declaraciones de monseñor Prigione, representante del papa en México, sobre el trabajo pastoral del obispo de Cuernavaca, Sergio Méndez Arceo, en julio de 1982, y la aceptación de la renuncia de éste al gobierno de la diócesis de Cuernavaca, por parte de Juan Pablo II, en enero de 1983 (Fazio, 1987), eran acciones que apuntaban a los intereses siempre manifiestos del Vaticano. Este entorno, sumado a las múltiples declaraciones de la jerarquía católica en los años de 1988 a 1991 en los medios de comunicación nacional, hacen plausible el planteamiento de Camp (1998: 57), en el sentido de que las verdaderas negociaciones sobre el contenido de esas reformas se habían iniciado entre representantes de la jerarquía eclesiástica y el gobierno federal en el transcurso de 1990.

En este marco, el protagonismo alcanzado por la institución eclesial durante la década de los ochenta le dotaron de fuerza política. Legitimado su derecho para emitir juicios en asuntos de orden político y su disposi- ción de mantener relaciones cordiales con el gobierno mexicano, aun a costa de su confrontación con obispos y ministros del ala progresista, encaradas por monseñor Prigione, la jerarquía católica orientó sus esfuerzos a romper con lo que reiteradamente definió como un simulacro legal. Estaba de su lado, un entorno sociopolítico que manifestaba la crisis inminente del sistema político mexicano, al que el nuevo presidente respondía con un proyecto de modernización económica neoliberal que exigía su correlato en los ámbitos político y social. ${ }^{12}$

En este marco, los acontecimientos fueron aparentemente abruptos: en su informe presidencial del 1 de noviembre de 1991, el presidente propuso reformas importantes al estatus constitucional de la Iglesia y de otras instituciones religiosas; el día 18 del mismo mes, la Cámara de Diputados aprobaba los cambios a los artículos 3, 4, 24, 27 y 130, publicados el 28 de enero de 1992 en el Diario Oficial. ${ }^{13}$ En marzo, la prensa nacional difunde que el presidente de la Fundación Cambio XxI, del PRI, formularía el reglamento que normaría los cambios constitucionales; el 25 de junio el pRI presenta ante la Cámara de Diputados una iniciativa de ley reglamentaria del artículo 130 constitucional $^{14}$, a la que se sumarían las iniciativas del PARM, PRD y PAN ${ }^{15}$; el 25 de junio se forma una comisión plural para conjuntar las cuatro propuestas presentadas e integrar una única propuesta; el 7 de julio se inicia la discusión del dictamen presentado por la comisión plural ante el pleno de la cámara, aprobándose el dictamen el día 8 de julio. ${ }^{16}$ Con 328 votos a favor, 36 en contra y dos abstenciones, la ley reglamentaria ya aprobada, fue turnada al Senado de la República y publicada en el Diario Oficial de la Federación el 16 de julio (Camp, 1989: 58; García, 1993: 103-127). ${ }^{17}$

Los contenidos normativos de la Ley de Asociaciones Religiosas y Culto Público, que marcan un punto de inflexión en las relaciones históricas entre las iglesias y el Estado mexicano pueden resumirse en los siguientes términos: 1) el reconocimiento a las iglesias y agrupaciones religiosas de personalidad jurídica como asociaciones 
religiosas;2) la igualdad de las asociaciones religiosas ante la ley en derechos y obligaciones, que le posibilitan la realización de actos de culto público religioso y la difusión de programas religiosos en los medios de comunicación masiva y de participar por sí o asociadas con personas físicas o morales en la constitución, administración, sostenimiento y funcionamiento de instituciones de asistencia privada, planteles educativos e instituciones de salud, siempre que no persiga fines de lucro y sujetándose también a las leyes que regulan esas materias; 3 ) el derecho de tener un patrimonio propio y la libertad para adquirir y enajenar bienes económicos y celebrar convenios jurídicos.

Este marco que legitima la participación de las iglesias en la vida pública, reitera el carácter laico del Estado y mantiene tres restricciones: la disposición de negar el voto pasivo a los ministros religiosos ${ }^{18}$; la prohibición explícita de no asistencia a los actos de culto con representación oficial de los funcionarios de nivel de la administración pública ${ }^{19}$; la prohibición de poseer o administrar concesiones para la explotación de medios de comunicación. $^{20}$

\section{La reforma constitucional en el contexto chiapaneco}

En Chiapas la coyuntura sociopolítica previa a la reforma constitucional de 1992 registraba diferencias importantes con la dinámica que operaba en el plano nacional. Por ejemplo, el contexto sociopolítico previo a la reforma constitucional no registra ninguna preocupación genuina o un debate abierto y directo entre opositores y partidarios sobre dicha reforma. A instancias de los medios nacionales, se registra que actores políticos y sociales externaron su desacuerdo hacia un cambio constitucional que alterara la Carta Magna de 1917, pero sin propiciar un diálogo interno, horizontal, amplio y directo.

De acuerdo con el reportaje de Excelsior y de otros diarios nacionales y estatales, los actores políticos externaron su desacuerdo. Patrocinio González Garrido, gobernador de Chiapas, reconocía que el sistema jurídico establecía con claridad los términos de la relación Iglesia-Estado y éste no requería de cambios ni en el artículo 130 ni en el artículo Tercero constitucional (Excelsior, abril, 1990). En igual sentido, el senador por Chiapas, Antonio Melgar Aranda, y el diputado federal por el $\mathrm{v}$ distrito electoral, con cabecera en la ciudad de Tapachula, César Ricardo Neumann Escobar, coincidían en señalar los inconvenientes históricos y reales por los que no debía reformarse el artículo 130 constitucional. Los sacerdotes, decían, se deben dedicar a su cometido y el Estado a lo suyo, respetándose mutuamente. Por su parte, el entonces presidente de la Barra Chiapaneca de Abogados, Servando Cruz Solís, declaró que las reformas a la constitución no debían hacerse por el simple hecho de la llegada del papa Juan Pablo II, pues de llevarse a cabo se harían interpretaciones contrarias a los principios históricos del país y se faltaría al respeto a uno de nuestros grandes próceres, Benito Juárez.

En contraste, la posición de los obispos, particularmente de las diócesis de Tapachula y de Tuxtla, coincidía con los de la jerarquía nacional. El primero, Luis Miguel Cantón Marín, consideraba que el artículo 130 era "obsoleto, vergonzoso, contrario a los tiempos modernos y a las reformas; por lo tanto, de no adecuarse, el gobierno tendrá falta de credibilidad". Para Aguirre Franco, obispo de Tuxtla, la iglesia no aceptaría "migajas" o "concesiones" en la reforma al 130 constitucional, al tiempo que subrayaba la "buena voluntad" del presidente Salinas de Gortari para reconocer la personalidad jurídica de la Iglesia, "como un acontecimiento entre las relaciones de México con el Vaticano". Para ambos obispos tanto el Estado como la Iglesia tienen la responsabilidad de velar por la paz y tranquilidad del país y de los mexicanos, así como contra quienes atentan contra la idiosincrasia, identidad y cultura nacional. Para el obispo de Tapachula, lo que deseaban del gobierno no era "un regalo, sino el recono- 
cimiento que nos corresponde", además de que "la Iglesia tiene más feligreses que cualquier partido político, por lo tanto su hasta ahora no reconocimiento legal obedece a tabúes políticos" (Berdejo, 1990).

\subsection{La reforma constitucional y la Iglesia católica en Chiapas}

El contexto sociopolítico chiapaneco previo a la aprobación de la reforma constitucional que, bajo la figura de "asociaciones religiosas", terminará otorgando personalidad jurídica a las iglesias, era mucho más complejo y manifestaba, en una porción estratégica del territorio chiapaneco, una tensión que pronto cobraría magnitudes insospechadas para la vida de los chiapanecos. Esta tensión, registrada ya desde los años setenta, tiene como actores centrales a la diócesis de San Cristóbal, presidida por su obispo Samuel Ruiz García y a los poderes e instituciones del gobierno estatal, quienes a lo largo de casi cuatro décadas van a ser protagonistas de una de las confrontaciones político-religiosas más significativas del Chiapas contemporáneo. Esta tensión no pudo ser ocultada por el ánimo institucional de las otras dos diócesis restantes, tampoco por el ambiente concertador que en el plano nacional caracterizaban a las relaciones IglesiaEstado, o por el contexto que, generado por la primera visita del papa y la segunda a realizarse en mayo de 1990, colocaba en una posición favorable a la fracción centrista de la jerarquía católica.

La diócesis de San Cristóbal enfrentaba serias tensiones con las corrientes conservadora y centrista de la jerarquía católica, pues en el marco del Concilio Ecuménico Vaticano II, había optado de manera abierta y radical por una acción evangelizadora que motivaba a las masas empobrecidas, a ser sujetos de su propio destino. ${ }^{21}$ En el contexto de Chiapas, esta opción pastoral le valió a la diócesis el repudio y el ataque directo de organizaciones que, como la Unión Regional de la Pequeña Propiedad y la Confederación Regional Ganadera, la acusaban de incitar a los campesinos a efectuar invasiones de tierras. El apoyo e impulso dado a las organizaciones sociales, particularmente las organizaciones campesinas e indígenas independientes, derivó en la confrontación también directa con el poder político estatal. El sentido político del quehacer pastoral de la diócesis y sus feligreses se expresaba en prácticas y movilizaciones orientadas no sólo a exigir la legitimación de su presencia como actores sociales en el territorio diocesano, sino también, desafiando al aparato gubernamental, a ejercer activamente el poder social y político alcanzado.

En este contexto, los pronunciamientos del obispo Samuel Ruiz García ante la visita del papa a Chiapas, estuvieron más enfocados a la dimensión social que a las posibles reformas constitucionales, manifestó que dicha visita tendría un impacto singular, toda vez que podría, el papa, establecer contacto con "una realidad lacerante, dolorosa pero esperanzadora” (Berdejo, 1990).

El protagonismo y el poder social que para entonces se había ganado la diócesis de San Cristóbal en su territorio social diocesano, era manifiesto en la estructuración del comportamiento político de una feligresía que veía al Estado mexicano no sólo ausente en la resolución de sus problemas de pobreza y marginación, sino lo que era peor, como el enemigo a vencer en tanto protector de la clase terrateniente. Así, la ausencia del Estado mexicano, particularmente en esta área de la geografía chiapaneca, había hecho de esta diócesis la institución que suplía las responsabilidades del gobierno; junto con la diócesis de Tapachula, suplió también a los gobiernos federal y estatal en la resolución de muchos de los problemas de miles de refugiados guatemaltecos en tierras chiapanecas. Durante el gobierno del general Absalón Castellanos Domínguez (1982-1986), cuando el conflicto agrario asumió dimensiones violentas, las organizaciones campesinas e indígenas independientes hicieron de la diócesis, presidida por el obispo Samuel Ruiz García, un referente moral y político importante. Un factor crucial en el desarrollo conflictivo entre la 
pastoral diocesana y los gobiernos estatal y federal, estaba dado por la preeminencia de la feligresía indígena, lo que les permitía disputarse así el control, la regulación y la orientación del cambio social en prácticamente todo el territorio indígena del área diocesana. ${ }^{22}$

Con la llegada de Patrocinio González Garrido a la gubernatura de Chiapas, en diciembre de 1988, las tensiones entre la diócesis y el gobierno cobraron dimensiones críticas que exigieron la atención de la jerarquía católica y del propio gobierno federal. La creación del Centro de Derechos Humanos "Fray Bartolomé de Las Casas" en 1990, le posibilitó a la diócesis romper los límites jurídicos impuestos a las instituciones religiosas y enfrentar, como asociación civil, las presiones del gobierno estatal, como fue el caso del encarcelamiento del sacerdote Joel Padrón, párroco del municipio de Simojovel, así como tener una participación activa en la defensa de los movimientos sociales y políticos de sus feligreses que reclamaban, desde la participación en la toma de decisiones del gobierno local y el respeto a las formas de elección comunitaria de sus representantes en los espacios gubernativos, hasta la discusión abierta de las políticas agrarias o neoliberales puestas en marcha por el gobierno federal. ${ }^{23}$

La mediación de la diócesis en la administración o resolución del conflicto entre la población campesina e indígena y el gobierno estatal, complicó los términos de las disputas. El obispo y sus agentes de pastoral prácticamente desafiaban a las autoridades locales y el protagonismo político alcanzado les posibilitaba situar el campo de negociación en la propia capital y con las autoridades federales, trascendiendo así no sólo la dimensión espacial local del conflicto y sus actores, sino incluso el carácter contingencial de las demandas, lo que colocó en una situación difícil al propio gobiemo federal.

En este contexto se dio la reforma constitucional en 1992. La diócesis de San Cristóbal, al crear ex profeso el Centro de Derechos Humanos Fray Bartolomé de Las Casas (CDHFBC), emitía informes, que como el de septiembre de 1991, denunciaba las graves violaciones a los derechos humanos de los indígenas de Chiapas y asumía pronunciamientos críticos al poder político local que poco después alcanzarán al gobierno de Carlos Salinas de Gortari y al modelo económico neoliberal asumido por éste. ${ }^{24}$ Como era de esperarse por parte de un grupo de la jerarquía católica, los pronunciamientos y ataques al obispo y a su diócesis, también subieron de tono, particularmente del nuncio apostólico, Girolamo Prigione, y de miembros del ala conservadora y centrista de la jerarquía católica mexicana. Las críticas, similares a las vertidas al obispo de Cuernavaca, a principios de los años ochenta, culminaron en agosto de 1993 con la solicitud de remoción de Samuel Ruiz.

Después de más de tres décadas, la diócesis enfrentaba una de las crisis más serias de su historia. La radicalización del discurso pastoral empezó a tener una respuesta igual de radical por parte del gobierno del estado. Era claro que la confrontación del gobernador Patrocinio González Garrido y de los grupos económicos dominantes de Chiapas no era con el conjunto de la Iglesia católica, sino con una de las diócesis, situación que de alguna manera explicaba la continuidad de las buenas relaciones entre los obispos de las dos diócesis restantes y el poder político estatal. El corolario de esta alianza y convergencia de intereses se vio reflejada en un evento social y religioso recordado por los chiapanecos: la boda de José Antonio González Blanco Ortiz Mena, hijo del gobernador, y Lilia Cristina Serrano Nájera, realizada en la iglesia de Nuestra Señora de Guadalupe, en la que estuvieron presentes, el nuncio apostólico del Vaticano, Girolamo Priogine, el arzobispo de Tlalnepantla, Manuel Pérez Gil, el cardenal de Guadalajara, Juan Jesús Posadas Ocampo, el obispo de Tuxtla, Felipe Aguirre y un sacerdote de Tuxtla (El Financiero, Informe Especial, 29 de enero de 1994). Aunque en ese momento, 25 de abril de 1993, Patrocinio González Garrido ya había sido removido de la gubernatura chiapaneca para ocupar en el plano nacio- 
nal, la Secretaría de Gobernación, el evento religioso realizado en tierra chiapaneca era significativo de las buenas relaciones entre la jerarquía católica y la clase política nacional y regional.

Los sucesos por venir, la entrada del Ejército Zapatista de Liberación Nacional (EZLN) al escenario político chiapaneco y nacional, le jugarán una cruda ironía a esta alianza y a sus actores. La irrupción del EZLN en tierras de la diócesis de San Cristóbal abrió una coyuntura que la colocó, particularmente a su obispo, Ruiz García, en una posición política privilegiada. ${ }^{25} \mathrm{El} 8$ de enero de 1994 es éste, ante petición expresa del gobierno federal, quien acepta fungir como mediador entre las partes en conflicto $^{26}$ (CONAI, 1999). La influencia política de la diócesis sobre los laicos, era reconocida con antelación al conflicto y se profundiza al asumir la intermediación. El impacto es difícil de medir, aunque dos hechos fueron evidentes: colocó al sistema político mexicano y a sus instituciones en una situación de grave fragilidad y, en el seno de la Iglesia católica, evidenció la creciente polarización que la venía caracterizando.

A raíz del conflicto y hasta fines 1999, la Iglesia católica en Chiapas, particularmente la diócesis de San Cristóbal, no sólo es un actor social legitimado formalmente por las reformas constitucionales, sino también un actor político de primer orden, reconocido no sólo por su feligresía, sino por el propio gobierno federal y estatal y por una parte significativa de los actores políticos y sociales, particularmente de quienes manifestaron de manera abierta y directa su apoyo al movimiento neozapatista. En sentido estricto, su participación en la mediación no tuvo un sentido sólo de fe y buena voluntad evangélica, sino de poder. En el fondo, estaba en juego el futuro social y político de la feligresía indígena y, sobre todo, el proyecto diocesano forjado por más de tres décadas. ${ }^{27}$

Ello explica las serias dificultades que enfrentó el diálogo y la negociación entre el gobierno, el EZLN y la Comisión Nacional de Intermediación (CONAI) presidi- da por el obispo Samuel Ruiz García, pues estaba en juego la primacía no de dos proyectos sino de al menos tres proyectos de futuro, aunque el discurso mostrara la confrontación entre un gobierno debilitado y un EZLN fortalecido y respaldado por la sociedad civil y las más diversas fuerzas políticas definidas genéricamente de izquierda o independientes; explica también el acompañamiento activo de una diversidad de instituciones civiles y organismos no gubernamentales que desafiando los límites reales entre religión y política, legitimaron el papel de la diócesis y la orientación que ésta imprimía al proceso de negociación.

Los acontecimientos posteriores, la desaparición de la CONAI, la crisis de las negociaciones entre el gobierno federal y el EZLN, la renuncia presentada al Vaticano por el obispo Samuel Ruiz García, el 25 de noviembre de 1999; la llegada de Raúl Vera como obispo coadjutor de la diócesis, el 29 del mismo mes, y la asunción de monseñor Felipe Arizmendi Esquivel al obispado de San Cristóbal, en abril de 2000, si bien marcan un punto de inflexión en el comportamiento político de la diócesis, ésta no disminuye su protagonismo en la vida pública de la entidad.

En efecto, aunque la separación del obispo Ruiz García de la diócesis no ha significado que la comunidad diocesana, formada por sacerdotes, religiosos, agentes de pastoral y feligreses, renuncien a una trayectoria pastoral largamente construida bajo el liderazgo de monseñor Ruiz García, es visible la reorientación que su sucesor, el obispo Felipe Arizmendi Esquivel, le ha impreso a la diócesis hacia las líneas vaticana y centrista de la CEM, cobijándose en el discurso de la modernización política, esto es, el de la transición y la pluralidad democrática. ${ }^{28}$ Por parte del nuevo obispo, es visible no sólo la asunción de un papel de observador crítico del ejercicio de los gobiernos federal y estatal y de las organizaciones de la sociedad civil, sino también la de un actor social y político capaz de colocarse en el espacio mismo de la toma de decisiones 
políticas y gubernativas o en la resolución de conflictos de los mismos órdenes.

\subsection{La reforma constitucional y las Iglesias protestantes, evangélicas, judaicas y bíblicas no evangélicas en Chiapas}

El contexto sociopolítico chiapaneco previo a la aprobación de la reforma constitucional, era totalmente desfavorable a las iglesias no católicas, pues tanto los actores de la Iglesia católica como los actores políticos, denunciaban el incremento sustantivo de los grupos no católicos en la sociedad chiapaneca, asumiendo que este hecho laceraba la identidad nacional. Para los obispos, las "sectas" religiosas, en su mayoría de origen estadunidense, atentaban contra la paz social y la unidad de los pueblos, y provocaban la desintegración familiar. Argumentaban que la colonización religiosa estadunidense se había vuelto preocupante, pues aunque toda persona era libre de profesar la religión que guste no se podía atentar contra la seguridad de un país y mucho menos provocar la falta de respeto y veneración para los símbolos patrios, como lo hacen las sectas religiosas. ${ }^{29}$

En este mismo tenor y con el mismo lenguaje estereotipado, la mayoría de los actores políticos y sociales se pronunciaban de manera negativa por la presencia activa en Chiapas de credos no católicos. El gobernador de Chiapas señalaba que en la entidad "no se permitirá a las sectas religiosas seguir con actos atentatorios contra la identidad nacional y los símbolos patrios, al amparo de la libertad y las creencias"; el senador por Chiapas, Antonio Melgar Aranda, y el diputado federal por el $v$ distrito electoral César Ricardo Neumann Escobar, coincidían en que las sectas religiosas manipulaban la voluntad de los ciudadanos y era un factor importante de penetración en la región indígena. "Los mexicanos tenemos cultura, tenemos historia y no podemos cambiarla de “tajo"; por lo tanto, decían, se debe analizar profundamente el riesgo que se corre con la libre actuación de las sectas por el peligro de que sigan socavando nuestra soberanía nacional". Para Jorge Moscoso Pedrero, entonces diputado local plurinominal del PRD, las sectas religiosas representaban un serio problema. El gobierno tenía mucha culpa de su actuación en contra de la paz y la tranquilidad social, porque "las ha dejado hacer lo que quieran". Denunciaba que "estos son grupos utilizados para crear conflictos, enfrentamientos e incluso provocar inseguridad, sobre todo en la región fronteriza, donde han incrementado su presencia, ya que los gobiernos federal y estatal no definen los recursos que se destinan para reforzar la identidad nacional" (Berdejo, 1990).

En este contexto no fue extraño que los representantes de las iglesias no católicas se abstuvieron de hacer pronunciamientos públicos en torno a la reforma constitucional, además de que existieron evidencias de que estas instituciones eclesiales no fueron convocadas institucionalmente en el debate sobre los términos del cambio constitucional $^{30}$ (Camp, 1998; García, 1993). Sin embargo, para una lectura objetiva sobre las razones del crecimiento de los credos no católicos, debe recordarse que desde la década de los ochenta, la realidad chiapaneca estaba siendo impactada por una crisis económica severa y, producto de las políticas de ajuste económico, por una crisis política donde era visible la erosión de un Estado mexicano comprometido con los idearios de la Revolución, lo que propiciaba en los sectores sociales más desprotegidos la búsqueda de sistemas de sentido alternativo, que de manera inmediata lo encontraron en un mercado religioso que ya contaba con una oferta diversificada de credos.

Las décadas de los ochenta y noventa son el periodo de mayor crecimiento de la feligresía no católica y lo cierto es que previo a la reforma constitucional, las iglesias no católicas le estaban imprimiendo a la sociedad chiapaneca, específicamente a la de los territorios con población indígena, una dinámica sociopolítica caracte- 
rizada por la confrontación y el conflicto, donde era evidente, a través de acciones y movilizaciones, el asalto al espacio público de unas feligresías que exigían su reconocimiento como actores sociales. Por ello, nada extraño que en la coyuntura generada por la visita del papa a Tuxtla Gutiérrez y los pronunciamientos de los actores políticos y eclesiales en la capital del país con respecto a la reforma constitucional, se aprovechara para que los actores locales más representativos argumentaran el efecto negativo que el desarrollo de éstas tienen en la cultura e identidad nacional, así como en el espacio comunitario de los pueblos indios. ${ }^{31}$

El conflicto religioso que ocurría en las regiones indígenas de Chiapas presentaba dimensiones que iban más allá de las confrontaciones intereclesiales, para colocarse en el campo de la política, pues, además de provocar tensiones con otras áreas de la vida social, cuestionaba de manera abierta un sistema de poder sustentado en las relaciones entre la "costumbre" y el corporativismo; entre la "costumbre" y el unipartidismo del régimen mexicano. La politización del conflicto religioso derivó en la expansión de espacios organizativos de mediación, sustentados en la defensa de los derechos humanos, particularmente los de libertad de creencia, e incorporándose dicha dimensión en las agendas de trabajo de muchas otras organizaciones locales y regionales $^{32}$ (Morquecho,1992).

Así, la reforma constitucional de 1992, que no tuvo como preocupación genuina el conflicto religioso manifiesto en el territorio nacional, abonó en un terreno donde el conflicto tiene expresiones profundamente políticas, lo que explica la continuidad, al menos durante los años noventa, de un patrón de resolución y administración del conflicto religioso que siguió recreando las viejas prácticas metaconstitucionales. Sin embargo, amén de otras variables, la reforma constitucional, que otorga personalidad jurídica a todas las asociaciones religiosas, independientemente de la antigüedad y el número de fieles, terminó por ser benéfica para las asociaciones religiosas no católicas.
En Chiapas, el amplio margen de acción que hoy tienen las asociaciones religiosas para realizar sus actividades de culto público y para promocionar u ofertar sus credos a través de estrategias de trabajo en los campos de la educación, la asistencia social y otras que le son propias a su fin, les ha abierto las posibilidades legales para cerrar el viejo modelo de administración y resolución de conflicto. En el campo político, las dirigencias eclesiales no católicas reconocen que la ley, aunque no totalmente como ellas quisieran, les permite actuar en el campo de la política, aunque el área de trabajo que le compete sea, en el campo de la cultura, el religioso. En este sentido, pese a su fragmentación, empiezan a sentirse corresponsables en la tarea pública y civil de dar dirección y sentido ya no sólo a su feligresía sino a la sociedad más amplia. Sobre el potencial social y político de las asociaciones religiosas no católicas, son ilustrativas las declaraciones de un pastor presbiteriano con fuerte arraigo en la región Altos, hechas al antropólogo y periodista Gaspar Morquecho.

"Las iglesias indígenas son las que más están creciendo. Más que las mestizas. Este es el motivo que originó que nos pidieran que entráramos a la radio con dos programas. Próximamente vamos a aparecer en la radio en la lengua tzotzil...". "los indígenas han abierto el camino en los aspectos libertarios y un ejemplo clásico es el de Chamula. Cuando estuvieron aquí en San Cristóbal, no sólo tuvieron diversidad religiosa, evangélica, sino diversidad política [...]. Algunos se volvieron nazarenos, presbiterianos, pentecosteses, adventistas [...]. Acá se convirtieron en panistas, perredistas, al regresar a Chamula llevaron esas dos aperturas: la política y la religiosa".

"Con 40 por ciento — de evangélicos—, podemos hacer mucho no solamente religiosamente, sino, políticamente en el estado. Pero tenemos que, primeramente, tratar de mantener la unidad, buscar consensos y eliminar ciertas cuestiones que a veces nos desunen". "Para el año 2000 debemos tener ya pautas 
y no solamente un evangelio de cuatro paredes, sino que tenga presencia, impacto. Tenemos que hablar con los evangélicos, somos ya 40 por ciento en Chiapas y todavía no podemos siquiera poner un diputado, no podemos tener nuestras radiodifusoras evangélicas y ya Marcos — subcomandante_- la tiene hasta en FM".

A la pregunta expresa ¿Qué pasó con esa idea de la asociación política? Respondió:

"Lo que pasó es que los evangélicos del centro y norte — del país— se aceleraron, dijeron: “¿para qué queremos una asociación política, vámonos a lo grande, vamos a un partido, y hasta formaron un comité de seguimiento. Hasta traían un nombre. Mas sin embargo, se dieron cuenta que muchos de los 18 millones de evangélicos estaban alineados al PRI. Otro porcentaje tenía compromisos con cargos políticos (...) esa falta de unidad y de conciencia, echó abajo eso. El proyecto de Chiapas, la de asociación evangélica quedó olvidada porque la tirada era, según las reformas del Código Federal Electoral, que se pudieran conformar las asociaciones políticas y que con esa asociación pudiéramos tener líderes de diferentes partidos y que cualquiera del liderazgo laico de la asociación política que ambicionara un puesto de elección popular [...], tendría que ir a un partido político para que lo avalara, pero vigilado por la asociación política evangélica. Vigilado y cuidado".

"[...] siento que no perdemos la esperanza de tener más presencia política, porque, a pesar de eso, yo he oído que están ahí con la inquietud, con la semilla y no pierden la esperanza. Están haciendo un trabajo de concientización poco a poco. Al principio tal vez aliándose” (Morquecho, 1998: 106-108).

En las elecciones de 2000 por la gubernatura del estado, el triunfo le correspondió al señor Pablo Salazar Mendiguchía, un miembro de la Iglesia Nazarena. Aun- que en este triunfo se cruzan varios factores, como una alianza de ocho partidos dispuestos a derrocar al PRI, el antecedente senatorial del candidato y su participación en la COCOPA, para muchos chiapanecos quedaron varias interrogantes ¿qué tanto influyó la dimensión religiosa en el triunfo electoral de Pablo Salazar Mendiguchía? ¿La feligresía no católica votó por el hecho de compartir con el candidato una identidad religiosa y derivar de ello que su triunfo les iba a dar mayores posibilidades de encauzar, por la vía de la política, la disputa por el control del monopolio religioso? ¿El voto de la feligresía no católica es hoy un factor estratégico que deben revalorar los partidos políticos?

\section{Religión y política en Chiapas. Algunas reflexiones a 12 años de la reforma constitucional}

Es difícil sostener que la decisión del presidente Carlos Salinas de Gortari de reformar la constitución en materia religiosa haya obedecido a las exigencias de modernización social y política del país, particularmente al reconocimiento de una sociedad que, frente a la crisis material y emotiva que la envuelve, reencuentra en la religión los fundamentos para normar sus relaciones con los otros. Resulta más creíble el argumento de una negociación entre el poder político y el eclesial católico, sabedores de la capacidad de control y regulación de las tendencias del cambio social que ambos poseen. Sin embargo, la reforma constitucional que otorga el estatuto legal a las asociaciones religiosas, amén de los derechos individuales de libertad religiosa y de culto, constituye un reconocimiento a la pluralidad de identidades sociales que exige un marco normativo de igualdad democrática (Blancarte, 1994; Zambrano, 2002).

El proyecto de reforma constitucional estuvo acompañado de un clima de recelo y sospecha. Era evidente la tensión que gestó en la jerarquía católica la aprobación de un marco normativo que colocaba a la Iglesia cató- 
lica en igualdad de condiciones a las asociaciones religiosas no católicas, sin considerar las diferencias de antigüedad y de número de fieles entre la primera y estas últimas. Las relaciones entre los representantes de la Iglesia católica y del Estado mexicano, si bien mantienen la ambivalencia y el clima de desconfianza que les ha caracterizado, es visible el peso hegemónico que la visión eclesial y el proyecto de país sustentado en una identidad católica-guadalupana, ejerce en amplios sectores populares y en restringidos pero importantes grupos conservadores de la sociedad nacional. ${ }^{33}$

Pero las pretensiones de la jerarquía eclesial católica que derivarían no sólo en un trato desigual a las asociaciones religiosas (Blancarte, 2001), sino en una confesionalidad nacional, si no es que en una teología de Estado (Zambrano, 2002), están mediadas por un escenario social que cotidianamente activa a una multiplicidad de identidades religiosas y no religiosas que se confrontan en la arena de los empoderamientos para transitar al campo de lo político en busca del reconocimiento o ejercerlo si ya lo tienen (Zambrano, 2002). Las pretensiones de la jerarquía católica, al igual que las otras jerarquías portadoras de otras tantas identidades, se ven mediadas también, salvo coyunturas álgidas, por una cotidianidad regional y local, cuyos actores particularizan las formas de obtención, de uso y desarrollo del poder que entraña la adscripción identitaria.

Estos planteamientos rezan también para las identidades religiosas no católicas y sus anhelos de asalto al espacio público. Las relaciones entre las iglesias no católicas y el poder estatal, suelen visibilizarse más en el espacio regional y local. Por ejemplo, Chiapas es una entidad representativa de la gestión y desarrollo de estas nuevas relaciones que, si bien se dan sobre la base de leyes de reconocimiento de derechos y obligaciones como cualquier otra asociación civil, y de reconocimiento de la superioridad del Estado como garante del orden social, están propiciando desarrollos religiosos y sociopolíticos dignos de tomarse en cuenta.
A este respecto, no es ninguna novedad el activismo social y político que hoy entraña el comportamiento de las elites religiosas no católicas, lo que les permite superar la asunción de "víctima" y transformar el discurso religioso en el soporte simbólico para emprender acciones que las coloca en el mundo de los intereses materiales, aduciendo por supuesto un "otro" opresor e injusto. No se intenta con ello decir que antes las iglesias no católicas redujeran sus acciones y prácticas al mundo trascendental, pues éstas, como señala la sociología de la religión, operan en contextos sociales, y al igual que impacta a dichos contextos es también impactada por éstos. Lo que se intenta decir, es que las asociaciones religiosas a partir de la reforma constitucional, adquieren una importancia tal en la vida pública que terminan por imprimir cambios en los términos de las relaciones con el Estado y los poderes públicos.

Apegado al nuevo marco normativo, la Secretaría de Gobernación ha creado una Dirección General de Asuntos Religiosos y como una derivación, su equivalente en la estructura de los gobiernos estatales, como es el caso de Chiapas, que creó en 1999 la Subsecretaría de Asuntos Religiosos y, en el marco de ésta, otras iniciativas que como la formación del Consejo Interreligioso delEstado de Chiapas $^{34}$, intentan ser los espacios de diálogo y de concertación en materia de resolución y administración de conflictos y de socialización de una cultura de paz y tolerancia.

Sin embargo, a estos cambios, a todas luces positivos, se están gestando otros que invocan a las relaciones de antaño, yque suelen tornarse visibles en los tiempos electorales. No se trata sólo de la participación legítima de las asociaciones religiosas en los procesos políticos y sociales del país, de la entidad o de la localidad, sino del impulso de estrategias que posibilitan la participación política de las asociaciones religiosas, asumiéndose como un poder en sí mismas o como espacios corporativos que orientan y modulan el comportamiento político de su feligresía para obtener beneficios directos del poder político. 
No es repetir la historia de la Iglesia católica, pues la sociedad ha cambiado de manera extraordinaria, de tal manera que es prácticamente difícil que el control y la regulación de las tendencias del cambio social sean atributo exclusivo de una religión u otra dimensión identitaria. Sin embargo, frente a un convulsionado escenario de fragmentaciones sociales y de una reversión dramática en el pacto redistributivo, no está ausente la tentación de encauzar a las masas hacia movimientos facciosos o hacia batallas políticas sustentadas en textos bíblicos que permiten justificar que Dios está con sus causas.

\section{Notas}

${ }^{1}$ Este tipo de acuerdo explícito entre la iglesia romana y los gobiernos para la resolución de tensiones en ámbitos mixtos (familia, educación, bienes materiales de la Iglesia), se sobrepone a las iglesias locales. "La relación Iglesia-Estado se define por acuerdo entre la Santa Sede y los estados nacionales sin pasar por los episcopados nacionales. [...] A las iglesias nacionales no se les deja iniciativas: se les pide que actúen dentro del marco trazado por los acuerdos entre Roma y los gobiernos" (Concha, et al., 1986: 22).

2 "El presidente fue mucho más allá de una declaración simbólica, haciendo evidente en numerosas medidas que la secularización ya no era una meta explícita de la administración. Además, los valores que tradicionalmente apoyaba la Iglesia — la unidad, el orden y la paz social— parecían coincidir con los adoptados por el liderazgo político" (Camp, 1988: 48).

${ }^{3}$ Esta idea la ejemplifica el autor, con el papel conservador asumido por el episcopado mexicano: aprobó una declaración subrayando los peligros del comunismo y ofreciendo ayuda al gobierno para oponerse a esa amenaza; $y$, frente a la matanza de Tlatelolco se abstuvo de un pronunciamiento cupular en contra de dicho acontecimiento y de brindar su apoyo y solidaridad a los estudiantes antes de la matanza. La única crítica, además de un grupo de sacerdotes, vino del obispo de Cuernavaca, Sergio Méndez Arceo, quien sin éxito propuso que dicho acontecimiento se examinara en la Conferencia Episcopal (Camp, 1998: 50).
4 “[...] la promoción de la justicia social pasa a ser una preocupación esencial de la vida del jesuita y la dimensión integral de las tareas apostólicas. De allí su nombre de "apostolado integral" [...]. En pocas palabras, "la salvación de Cristo se realiza por y en la liberación de los oprimidos, con el riesgo de que el Evangelio aparezca subversivo para el orden establecido" (Meyer, 1981:17).

${ }^{5}$ Socialismo democrático es una frase emitida por Méndez Arceo en una conferencia presentada, el 17 de julio de 1970, en la Preparatoria Popular de la Universidad de Puebla: "Creo que un sistema socialista es más conforme con los principios cristianos de verdadera fraternidad, de justicia y paz" "No sé qué forma de socialismo, pero ésa es la línea que debe seguir Latinoamérica. Por mi parte, creo que debe ser un socialismo democrático". Sobre este tema, Ignacio Pérez de León, director del Comité Nacional para el Ecumenismo, abundó: "El socialismo democrático es el único sistema que actualmente puede ser compatible con las exigencias del mundo cristiano y del Evangelio, en vista de que se balancea muy bien lo que es la realidad sociedad con la realidad persona humana (Fazio, 1987: 13 y 17).

${ }^{6}$ Véase por ejemplo, la entrevista hecha por periodistas a monseñor Prigione, representante de Juan Pablo II en México y la carta sobre la unidad de la Iglesia en Nicaragua de Juan Pablo II, en donde condenó, el 28 de julio de 1982, la existencia de la "Iglesia Popular" (Fazio, 1987).

${ }^{7}$ Cabe anotar que si bien la teología de la liberación, materializada en las Comunidades Eclesiales de Base (CEB), fue uno de los proyectos más acabados que se confrontó con la corriente conservadora dominante de la Iglesia católica mexicana, también emergieron diversas agrupaciones y movimientos eclesiales, promovidos desde el Vaticano II que, como Acción Católica y, más tarde, el Movimiento de Renovación en el Espíritu Santo, rompen con la idea de una jerarquía eclesial homogénea y abren, entre las distintas fracciones, un campo de lucha abierta por el consenso y la hegemonía institucional y social.

${ }^{8}$ Este reportaje, en doce partes, fue realizado por Alejandro Berdejo, y se publicó, como reporte especial, en Excelsior, entre el 10 y el 21 de abril de 1990.

${ }^{9}$ La CIRM agrupa a 250 institutos y tiene algo más de 40,000 afiliados en todo el país (Berdejo, 1990).

${ }^{10}$ En la XLVI Asamblea Plenaria realizada en Torreón, los miembros del Episcopado mexicano acordaron revisar un 
documento, que se presentaría más tarde al presidente, en el que se pide la modificación de los artículos 3, 24, 27 y 130 de la Carta Magna de 1917. (Berdejo, 1990).

${ }^{11}$ Agregaba: "que el Papa venga cuando quiera, a los católicos les dará mucho gusto pero deben tener presente que no se puede reconocer los derechos políticos a un individuo que abiertamente obedece a una institución extranacional" (citado por Berdejo, 1990).

${ }^{12}$ Para Roderic Ai Camp tres son los cambios en el contexto político que permitieron condiciones favorables para la introducción de reformas constitucionales: las reformas electorales y el consecuente aumento de la oposición política; la creciente erosión del liderazgo político y de las instituciones políticas; y, la expansión de los grupos populares católicos a consecuencia del sismo de 1985 en la capital (ibid: 52).

${ }^{13}$ Decreto por el que se reforman los artículos $3^{\circ}, 5^{\circ}, 24,27$, 130 y se adiciona el artículo decimoséptimo transitorio de la Constitución Política de los Estado Unidos Mexicanos, 28 de enero de 1992 (véase García, 1993, sección de anexos).

${ }^{14}$ Iniciativa de Ley Reglamentaria presentada por el grupo parlamentario del Partido Revolucionario Institucional, "Ley de Asociaciones Religiosas y Culto Público", 25 de junio de 1992 (véase García, 1993, sección de anexos).

${ }^{15}$ Iniciativa de Ley Reglamentaria presentada por el grupo parlamentario del Partido Auténtico de la Revolución Mexicana, "Ley Federal de Cultos", 18 de junio de 1992; Iniciativa de Ley Reglamentaria presentada por el grupo parlamentario del Partido de la Revolución Democrática, "Iniciativa de Ley en Materia de Libertades Religiosas", junio de 1992; Iniciativa de Ley Reglamentaria presentada por el grupo parlamentario del Partido Acción Nacional, "Ley de Libertades y Asociaciones Religiosas", 25 de junio de 1992 (véase García, 1993, sección de anexos).

${ }^{16}$ Dictamen elaborado por la Comisión de Gobernación y Puntos Constitucionales de la Cámara de Diputados del H. Congreso de la Unión, 8 de julio de 1992 (García, 1983: 224-261). ${ }^{17}$ Diario Oficial de la Federación. Ley de Asociaciones Religiosas y Culto Público, 15 de julio de 1992.

${ }^{18}$ Los ciudadanos mexicanos que ejerzan el ministerio de cualquier culto, tienen derecho al voto en los términos de la legislación electoral aplicables. No podrán ser votados para puestos de elección popular, ni podrán desempeñar cargos públicos superiores, a menos que se separen formal, material y definitivamente de sus ministerios cuando menos cinco años en el primero de los casos, y tres en el segundo, antes del día de la elección de que trate o de la aceptación del cargo respectivo. Por lo que toca a los demás cargos, bastarán seis meses". Tampoco podrán los ministros de culto asociarse con fines políticos ni realizar proselitismo a favor o en contra de candidato, partido o asociación política alguna (Ley de Asociaciones Religiosas y Culto Público, Capítulo Segundo, artículo 14).

${ }^{19}$ Las autoridades federales, estatales y municipales no intervendrán en los asuntos internos de las asociaciones religiosas. [...] no podrán asistir con carácter oficial a ningún acto religioso de culto público, ni a actividades que tenga motivos o propósitos similares. En los casos de prácticas diplomáticas, se limitarán al cumplimiento de la misión que tengan encomendada, ... (Ley de Asociaciones Religiosas y Culto Público, Título Cuarto, Artículo 25).

20 "Las asociaciones religiosas y los ministros de culto no podrán poseer o administrar, por sí o por interpósita persona, concesiones para la explotación de estaciones de radio, televisión o cualquier tipo de telecomunicación, ni adquirir, poseer o administrar cualquiera de los medios de comunicación masiva. Se excluyen de la presente prohibición las publicaciones impresas de carácter religioso" (Ley de asociaciones Religiosas y Culto Público, Capítulo tercero, Artículo 16).

${ }^{21}$ De acuerdo con la experiencia diocesana, entre sus resultados destaca la emergencia "de un pueblo consciente de que debe ser sujeto de su propio destino, que se articula y se organiza en la búsqueda y reclamación de sus derechos" (Ruiz García, 1989: 21).

${ }^{22}$ El área de trabajo de la diócesis de San Cristóbal abarca 48\% de territorio estatal en el que se asientan 47 municipios, de las regiones Altos, Selva, Norte y Fronteriza.

${ }^{23} \mathrm{Al}$ calor de ciertas coyunturas sociopolíticas, la diócesis no sólo creó ex profeso organizaciones civiles para que en los distintos campos de la vida social atendieran a su feligresía, sino también apoyó y avaló el desarrollo de una multiplicidad de organizaciones no gubernamentales, nacionales y locales, mismas que le acreditaron el apoyo moral y político frente a las acusaciones gubernamentales (véase, García, 1995 y 1997 ).

24 “"...] no toma en cuenta los elementos propios de la diversidad de los pueblos. Parece que la modernidad los quiere eliminar, como si en vez de un aporte y riqueza humana fueran un estorbo [...]; el pueblo está inconforme. Hay desnutrición y enfermedades provocadas por la pobreza". [...] casi no se 
nos permite nuestra opinión por parte de las autoridades [...]. En las elecciones nos obligan a votar por el partido oficial, el PRI" (ElFinanciero, Informe especial, 29 de enero de 1994).

${ }^{25}$ Un ejemplo ilustrativo de los alcances que tiene la jerarquía católica local sobre su papel en la vida de los chiapanecos, es el hecho de que un día después de la irrupción del EZLN, cuando el discurso gubernamental cierne sobre la diócesis de San Cristóbal las acusaciones de ser promotora activa del conflicto, los obispos se autoproponen como mediadores del conflicto: "Consideramos nuestras posibilidades reales de intermediarios, dado el ascendiente moral que se reconoce a la Iglesia" (Véase el segundo comunicado de los obispos de Chiapas, Domingo de Epifanía, enero 2 de 1994 (CONAI, 1999: 6).

${ }^{26} \mathrm{La}$ aceptación de mediación por parte del obispo Ruiz García se publicó en La Jornada el 8 de enero de ese año (CONAI, 1999: 7). ${ }^{27}$ Sobre el proyecto diocesano y su articulación con los movimientos populares y sociales, véase; Morales,1992 y 1998 ; González, 1989; Cuellar, 1994, Villafuerte, et al., 2002.

${ }^{28} \mathrm{Al}$ emitir, ante los medios de comunicación, un balance de sus cuatro años de obispado en la diócesis de San Cristóbal, Arizmendi Esquivel manifestó: "Me siento contento porque hemos ido aprendiendo a vivir en la pluralidad, tanto a nivel social y político como a nivel religioso, tanto al interior de la diócesis como con otras religiones; somos todos muy diferentes, hay gente muy de izquierda y de derecha, gente muy tradicionalista y gente muy avanzada, lo importante ha sido que vamos aprendiendo a convivir". Aunque insiste en el proyecto de una iglesia autóctona, liberadora, evangelizadora, para muchas organizaciones cercanas a la diócesis, éste no tiene que ver con el proyecto de teología india impulsado por el anterior obispo (Cuarto Poder, 2 de mayo de 2004).

${ }^{29}$ Una revisión a las notas periodísticas de esos años es ilustrativa del sentimiento de rechazo que tanto actores políticos y sociales, como intelectuales y académicos expresan hacia los credos no católicos. En Chiapas, véase por ejemplo, la revista Ámbar, noviembre de 1989, particularmente el artículo de monseñor Samuel Ruiz García: "Sectarismo: la división religiosa en Chiapas".

${ }^{30}$ En los reportajes hechos por Berdejo, sólo se registran dos declaraciones. La primera de Cléber Salazar Mendiguchía, entonces presidente de la Alianza Evangélica en el estado, en el sentido de que la Iglesia católica iba perdiendo presencia ante las sectas protestantes que "dan mayores oportunidades". La segunda, de Jesús Flores Carrillo, presidente del grupo Lerdo,
"Asociación Política Nacional" (APN) que agrupa a las sectas evangélicas a excepción de los Testigos de Jehová, quien manifestó que en Los Altos de Chiapas se habían expulsado a 15 mil seguidores, quienes pasarán a engrosar los cinturones de miseria de la ciudad de San Cristóbal de Las Casas (Berdejo, 1990). ${ }^{31}$ Para el obispo Ruiz García, no era casual que la mayor invasión de las secta y de movimientos espiritualistas de muy diversa índole se dieron después de la victoria del sandinismo en Nicaragua y del crecimiento de los movimientos de liberación. Reconoce que la primera reacción es la violencia, en tanto la "comunidad católica se siente invadida y agredida y así su reacción es también violenta: demolición de los lugares de culto, oposición a que se construyan templos o expulsión de los conversos" (Ruiz García, 1989: 19).

${ }^{32}$ Cabe recordar organizaciones de base como el Comité de Defensa de Amenazados, Perseguidos y Expulsados de Chamula; el Consejo Regional Indígena de los Altos de Chiapas (CRIACH); la Organización Indígena de los Altos de Chiapas (ORIACH); Organización de Pueblos Evangélicos de los Altos de Chiapas (OPEACH). Entre las organizaciones de defensa a los derechos humanos creadas en el marco de las Asociaciones Religiosas no católicas, destacan el Comité Estatal de Defensa Evangélica de Chiapas, (CEDECH); la Alianza Evangélica Ministerial de Los Altos de Chiapas y la Comisión Evangélica de Derechos Humanos (CEDH).

${ }^{33} \mathrm{En}$ referencia a la Carta Pastoral titulada "Del encuentro con Jesucristo a la solidaridad con todos; El encuentro con Jesucristo, camino de conversión, comunión, solidaridad y misión en México en el umbral del tercer milenio", Roberto Blancarte reconoce que es un proyecto en franca oposición a todo proyecto modernizador, en tanto se inscribe en una corriente de ideas que se generaron en América Latina y más específicamente en el Cono Sur, desde fines de los años setenta del siglo xx, y desarrollada en las dos décadas siguientes [...]. Se trata de "un discurso sociológico católico que busca demostrar que la identidad cultural latinoamericana tiene un inherente sustrato católico que es sólo compatible con la modernidad barroca, alternativa a la modernidad ilustrada” (Blancarte, 2001). ${ }^{34}$ Este Consejo está integrado por las iglesias Presbiteriana, Bautista, Pentecostés, Adventista, Nazarena, El Concilio Nacional de Las Asambleas de Dios, Iglesia de Dios Vivo, Columna y Apoyo de la Verdad, La Luz del Mundo, La Iglesia de Jesucristo de los Santos de los Últimos Días y las tres diócesis de la Iglesia Católica. 


\section{Bibliografía}

Berdejo, Alejandro, 1990. "Historia de acercamientos y rupturas Relaciones Estado-Iglesia”, doce partes, Excelsior, del 10 al 21 de abril de 1990, México.

Blancarte, Roberto. 1994. "Por un espacio de debate y tolerancia”, en Elpapel de las Iglesias en el México de boy, Secretaría de Gobernación/unam/Universidad Americana de Acapulco/Centro de Estudios de las Religiones en México, México, pp. 19-24.

—, 2001, "Iglesia y Estado: las dos espadas", en Nexos, pp. 48-57, número 282, junio, México.

Camp, Ai Roderic, 1998. Cruce de espadas. Politica y religión en México, Siglo Veintiuno Editores, México.

Comisión Nacional de Intermediación. 1999. Archivo Histórico. Comunicados de la Comisión Nacional de Intermediación de 1994 a 1998, Serie: "Senderos de Paz", Cuaderno Núm. 1, México. Cuéllar Vázquez, Angélica. 1994. "Xi Nich, el rostro de la dignidad indígena. La lucha de los indígenas por sus derechos humanos", en Miguel Concha Malo, 1994. Los derechos politicos como derechos humanos, La Jornada Ediciones, CIIH-UnAM, México, pp.137-152.

Decreto por el que reforman los artículos $3^{\circ}, 5^{\circ}, 24,27,130$ y se adiciona el artículo decimoséptimo transitorio de la Constitución Política de los Estados Unidos Mexicanos, Diario Oficial de la Federación, 28 de enero de 1992, México.

Fazio, Carlos, 1987. La cruzy el martillo, editorial Joaquín Mortiz Planeta, México.

García Ugarte, Martha Eugenia, 1993. La nueva relación IglesiaEstado. Una análisis de la problemática actual, Nueva Imagen, México.

García Aguilar, María del Carmen, 1995. Las organizaciones de la sociedad civil en Chiapas, Asociación para el Desarrollo de la Investigación Científica y Humanística en Chiapas, A. C., San Cristóbal de Las Casas, Chiapas, México.

—, 1997.'Las organizaciones no gubernamentales en Chiapas: algunas reflexiones en torno a su actuación política", Anuario 1997, Universidad de Ciencias y Artes de Chiapas, Tuxtla Gutiérrez, Chiapas, México, pp. 37-80.

González Esponda, Juan, 1989. Movimiento campesino chiapaneco 1974-1984, dos volúmenes, tesis de licenciatura en Economía, Área de Ciencias Sociales, Universidad Autónoma de Chiapas, San Cristóbal de Las Casas, Chiapas, México.
Instituto Nacional de Estadística, Geografía e Informática, Chiapas, XI Censo General de Población y Vivienda, 1990, Aguascalientes, México, 1991.

Instituto Nacional de Estadística, Geografía e Informática, Chiapas, XII Censo General de Población y Vivienda, 2000, Aguascalientes, México, 2001.

Mees, Ludger. 1998. “¿Vino viejo en odres nuevos? Continuidades y discontinuidades en la historia de los movimientos sociales", en Pedro Ibarra y Benjamín Tijerina, Los movimientos sociales. Transformaciones politicas y cambio cultural, Editorial Trotta, Madrid, pp. 291-320.

Meyer, Jean. 1981. "Disidencia jesuita. Entre la cruz y la espada", Nexos, Año IV, Vol.4, Núm. 48, diciembre, México.

Morales Bermúdez, Jesús. 1992. El Congreso Indígena de Chiapas: un testimonio, Anuario, 1991, Instituto Chiapaneco de Cultura, Tuxtla Gutiérrez, Chiapas, México, pp. 242-370. Morquecho Escamilla, Gaspar, 1998. "La diversidad religiosa en Chiapas. Una perspectiva evangélica: entrevista con el pastor Abdías Tovilla, en Chiapas: el factor religioso, Revista Académica para el estudio de las religiones, México, pp. 95-116.

Morquecho Quintanilla, Gaspar, 1992. Los indios en un proceso de organización. La Organización Indigena de los Altos de Chiapas, tesis de licenciatura en Antropología Social, Escuela de Ciencias Sociales, UNACH, San Cristóbal de Las Casas, Chiapas.

Rivera Farfán, Carolina, María del Carmen García Aguilar, Miguel Lisbona Guillén, Irene Franco Sánchez, 2004. Diversidad religiosa y conflicto en Chiapas. Intereses, utopias, realidades, UNAM, СОCYTECH, CIESAS, en prensa.

Ruiz García, Samuel, "Sectarismo: la división religiosa en Chiapas" en Ámbar, número 1, Nueva Época, noviembre de 1989, Tuxtla Gutiérrez Chiapas, México, pp. 19-21.

Villafuerte Solís Daniel, Jesús Morales Bermúdez, Gabriel Ascencio Franco, María del Carmen García Aguilar, Carolina Rivera Farfán, Miguel Lisbona Guillén, Salvador Meza Díaz, 2002. La tierra en Chiapas. Viejos problemas nuevos, FCE., México. Zambrano, Vladimir Carlos, 2002. Confesionalidad y politica. Confrontaciones multiculturales por el monopolio religioso, Universidad Nacional de Colombia, Facultad de Derecho, Ciencias Sociales, Colombia.

ElFinanciero, "Las trampas de la Fe". Informe Especial, 29 de enero de 1994, México, pp. 17-22.

Ley de Asociaciones Religiosas y Culto Público, Diario Oficial de la Federación, 15 de julio de 1992, México. 